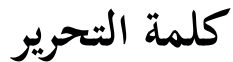

\section{الثيخ طه جابر العلواني: عالم ومفكر فقدناه}

بقلم رئيس التحرير

كان من أقدار الله سبحانه أن يُولد الشيخ طه جابر العلواني يوم ع مارس (آذار)

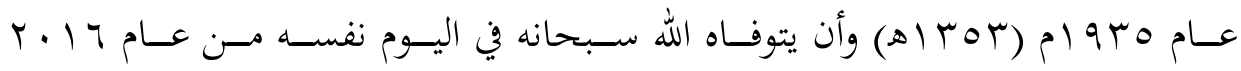

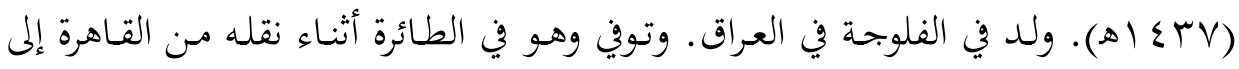
واشنطن لاستكمال علاجه.

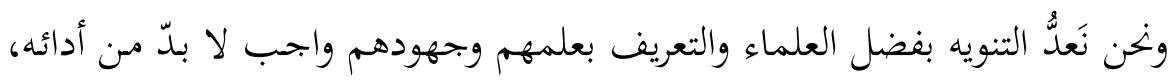

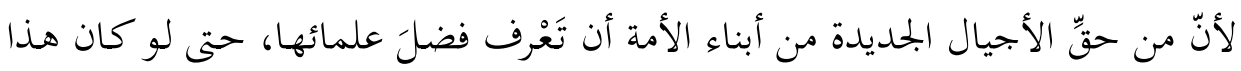
التنويه والتعريف لا يصل إلى مستوى الكفاية.

تتلمذ الشيخ طه على كبار علماء العراق في أربعينيات القرن الماضي حتى الثانوية

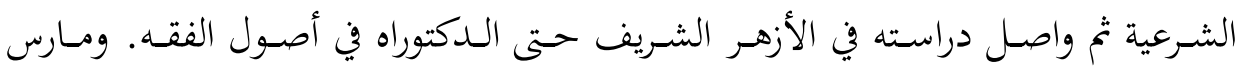

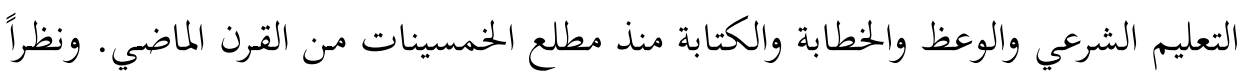

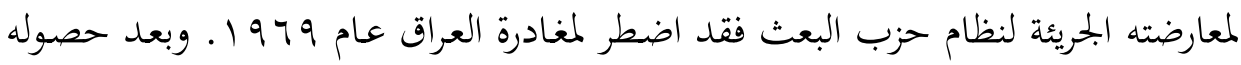

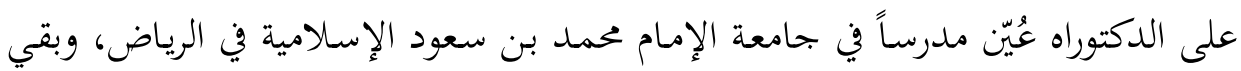

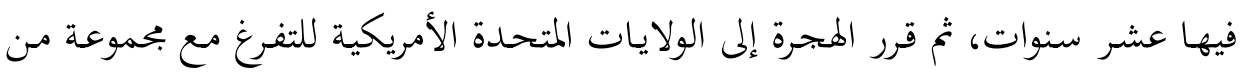

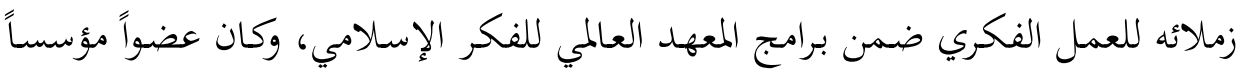

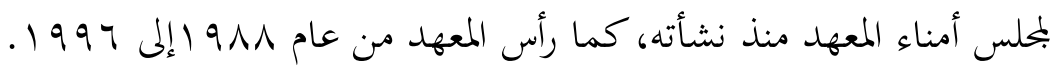

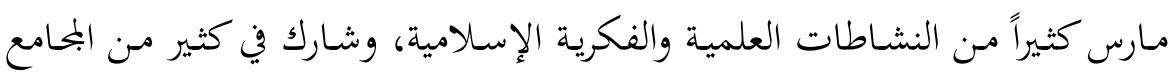

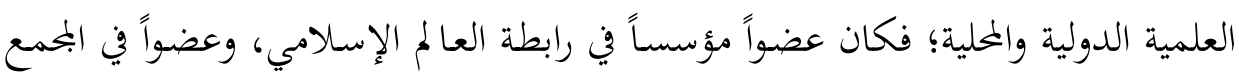

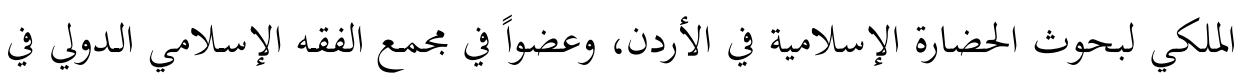

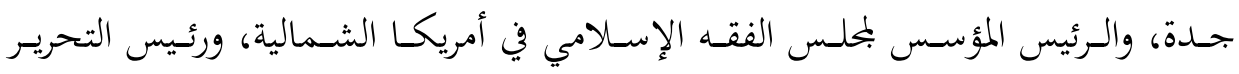


المؤسس لمحلة إسلامية المعرفة، والرئيس المؤسس لجامعة العلوم الإسلامية والاجتماعية في

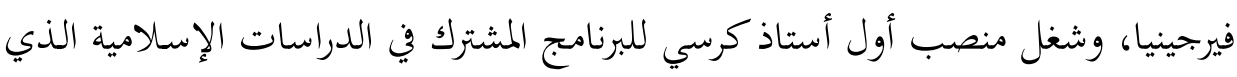
تُقدِّمُهه عشر جامعات أمريكية في منطقة واشنطن العاصمة. وغير ذلك كثير.

من أبرز ما عُرف بـه حرصه على التعليم والتعلم؟ ففي بحال التعليم فإنه لم ينقطع

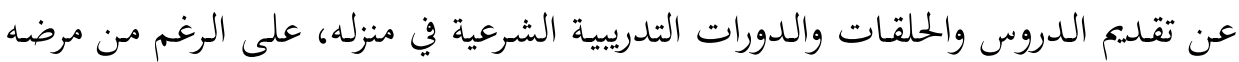

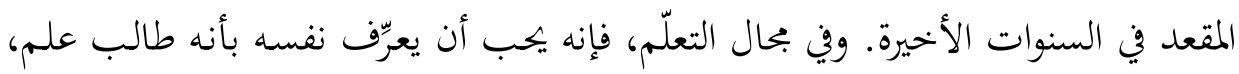
يرغب أن لا يقف في علمه وفكره على تخصص محدد، ويحرص على أية مناسبة تتاح له

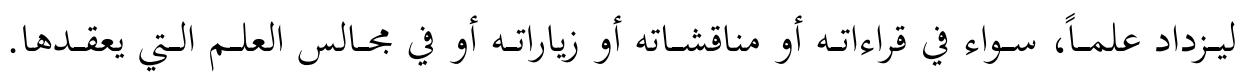
فكان دائم النمو والتطوير في صياغة أفكاره وتوضيحها وإعادة النظر فيها، مـن خهاءلال

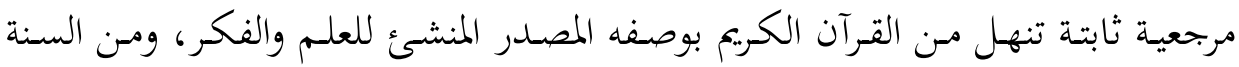

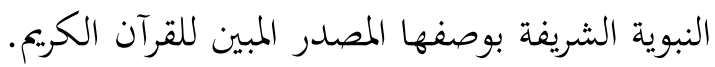

تنقَّل في اهتماماته وكتاباته العلمية من التخصص الأكاديمي في أصول الفقه، إلى فقه

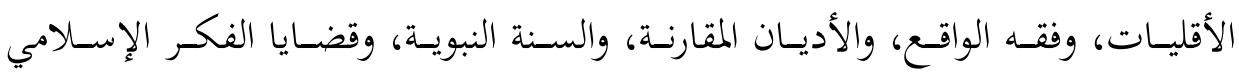

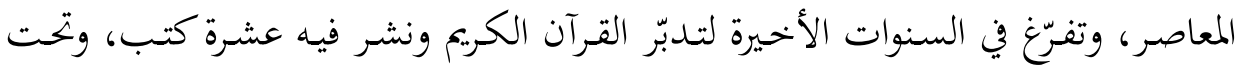

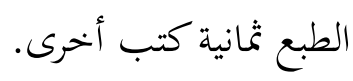

للشـيخ طه العلـواني حافظة وذاكرة، تلمسـها في سـهولة حضـور النص مـن القـرآن

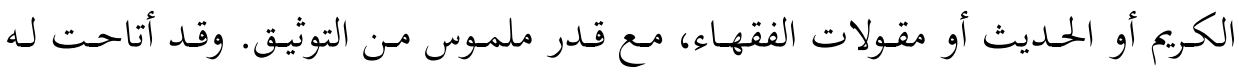

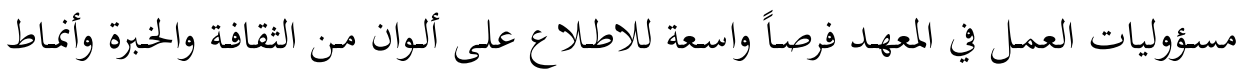
التفكير، ولاستكشـاف التحـديات التي على المفكـر الإسـلامي المعاصـر أن يواجهرهـا.

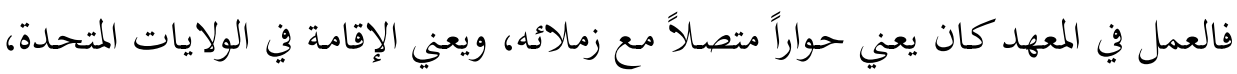

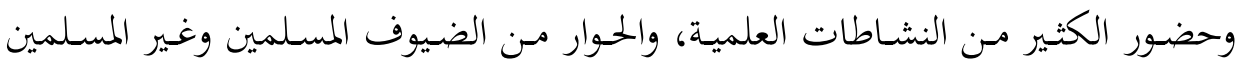

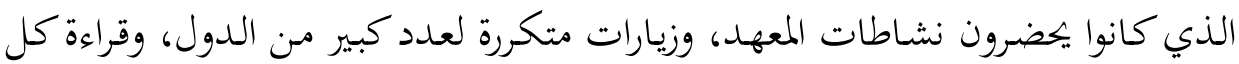

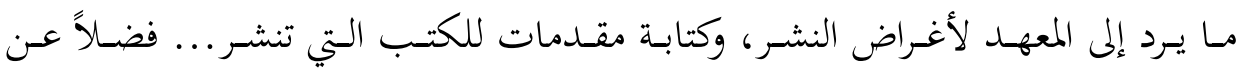
عضويته لكثير من المحامع الفقهية والعلمية، أتاح له كل ذلك فرصاً للنمو وسعة الأفق. 
نستطيع أن نعرّف بالشـيخ العلـواني قبـل مغادرته العـراق عـام 979 (1، بأنسه فقيـه،

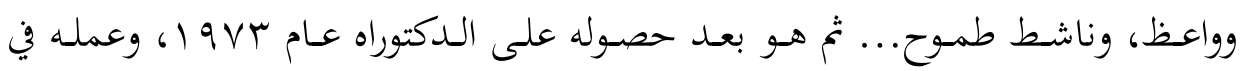

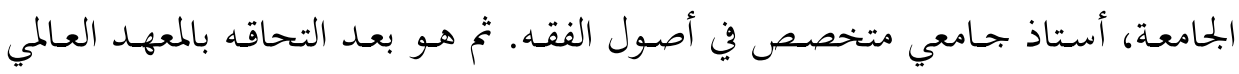
للفكر الإسلامي، عالم، ومفكر، ومصلح.

وربمـاكـان التحاقه بمجموعـة المعهـد حسدَثاً مهمـاً ليس له فحسب وإنمـا للمجموعـة نفسها، فعندما يروي الدكتور عبد الحميد أبو سليمان تاريخ تكوين هذه المحموعة ونشأة

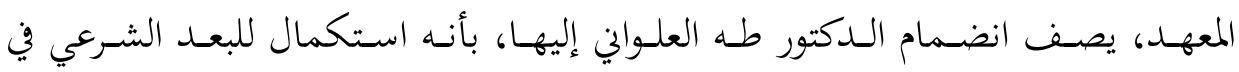
المحموعة. وتصف الدكتوره نادية مصطفى دور الدكتور العلواني في توجيه فرق البحث في

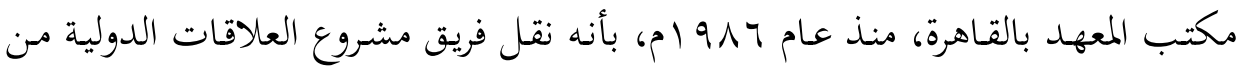

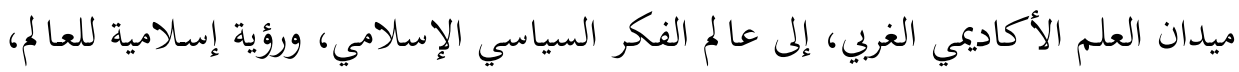
قادت خطى الفريق ولا تزال حتى اليوم.

وقد يكون مـن الإنصاف أن نؤكد أنه ليس مـن السهـل فصل إسهامات أي عضو

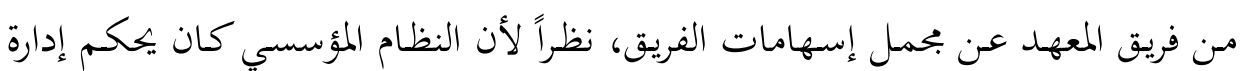

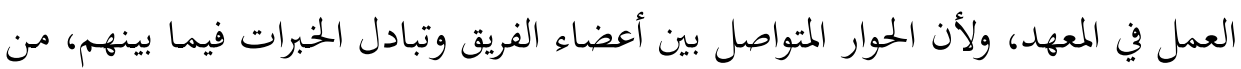

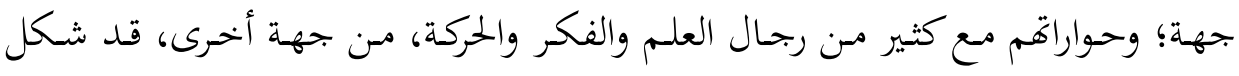

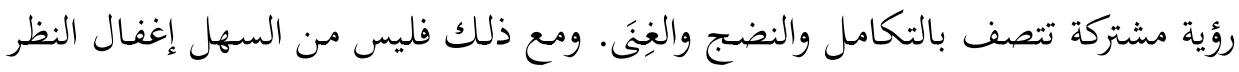
في البصمة الشخصية لكل عضو في الفريق.

وربما يبدأ حضور الشيخ طه وخبرته في نشاطات بحموعة المعهد، بصورة واضحة،

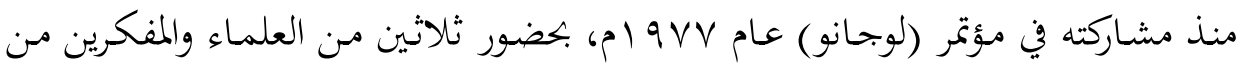

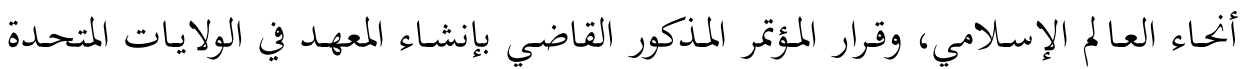
الأمريكية، والاستعداد للتفرغ للعمل الإسلامي الفكري في المعهد.

وقد كان اجتماع البمموعة في مكان واحد في مقر المعهد بولاية فيرجينيا الأمريكية،

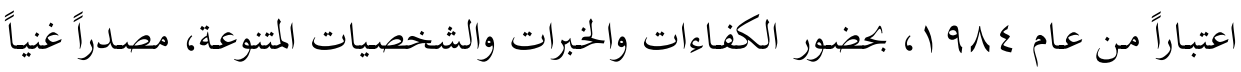
لوضع كل مـا امتلكه الشيخ طه مـ علم وخبرة في سياق جديد يتصف بأفق إسلامي 


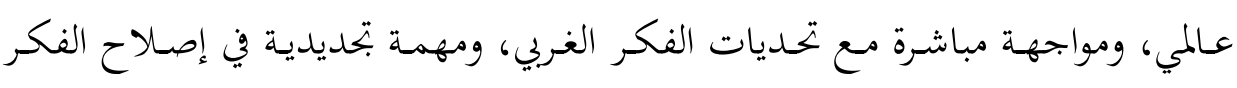

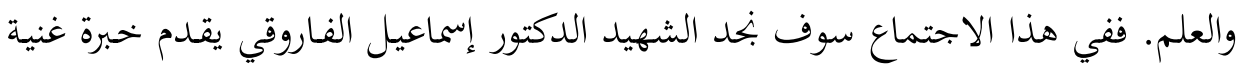

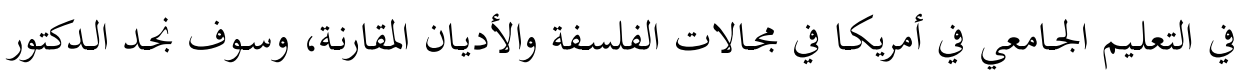

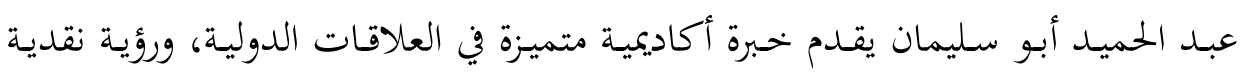

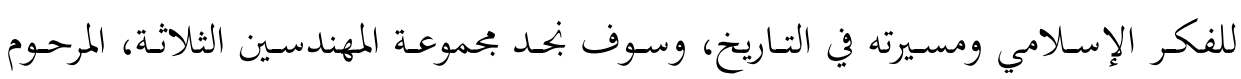

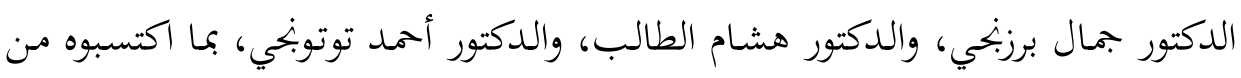

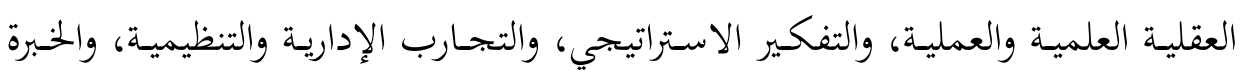

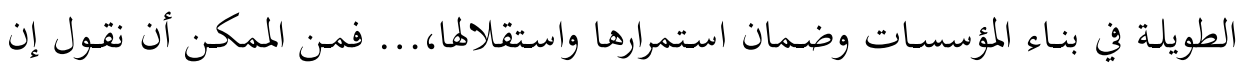

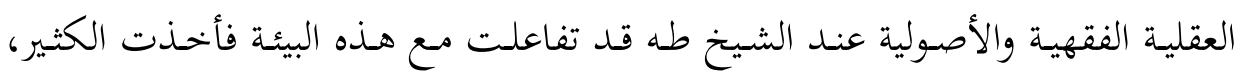
وأعطت الكثير.

وتبدأ مرحلة مميزة في إسهامات الشيخ طه عندما تقرر أن يتفرغ الدكتور عبد الحميد أبو سليمان لإدارة الجامعة الإسلامية العالمية في ماليزيا، ويتفرغ الدكتور طه العلواني لرئاسة

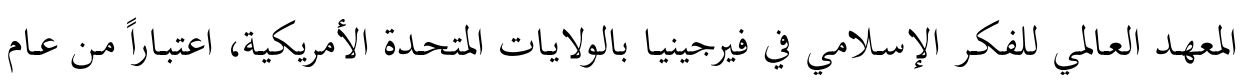

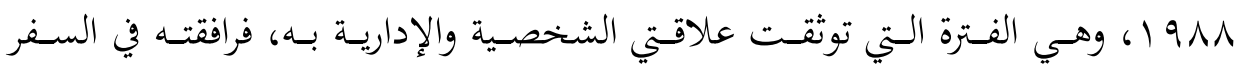
والحضر، وأشركني في الأعمال العلمية والإدارية، فرأيت فيه بحق مدرسة في الأدب والخلق

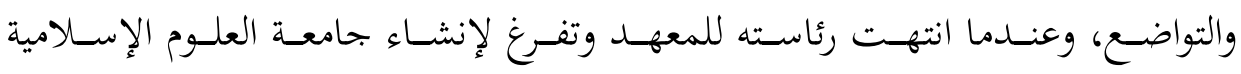

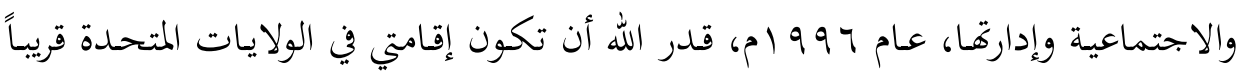
مـن إقامتـه، فأشركني في التخطيط لبرامج الجامعـة، وكـان عملي في المعهـد يتم بمشـورته

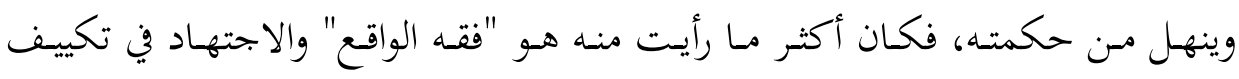
الموقف الشرعي الذي يحقق مقاصد الإسلام في ذلك الواقع. وكان من إدراكه لهذا الفقه

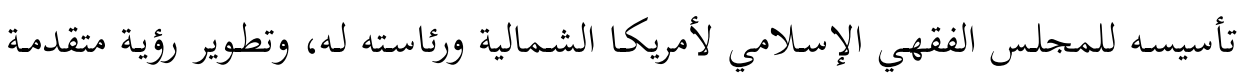
لفقه الأقليات، وهو فقه يصعب أن يتقنه من لم يعايش الأقليات ويعاني ما تعانيه.

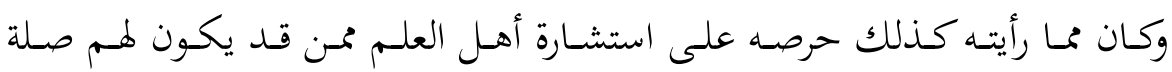
بالقضية التي تعرض للفتوى. دون أن ينسى كذلك استشـارة علمـاء الأمـة في مـواطنهم 
المختلفـة في المحتمعات الإسـلامية وبحتمعـات الأقليـات المسـلمة. فكانت فتواه أقرب مـا تكون إلى الاجتهاد الجماعي.

هذا الحرص على استكمال معطيات العلم اللازمة لبيان الحكم الشرعي، كان يوازيه

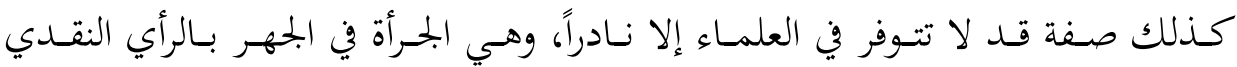

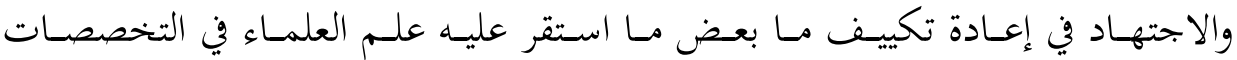

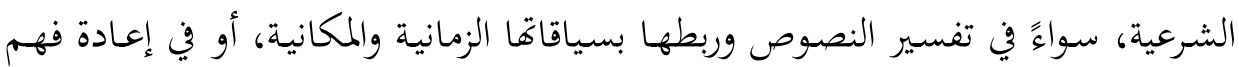
الحكم الفقهي المدون في ضوء حاكمية القرآن وهيمنته.

كثيراً ما كان الشيخ طه يروي مواقف حوارية مع بعض العلماء من أساتذته وزملائه حول آرائهم النقدية لبعض الأحكام والفتاوي المستقرة، واعترافهم بعدم توفر الجرأة لديهم

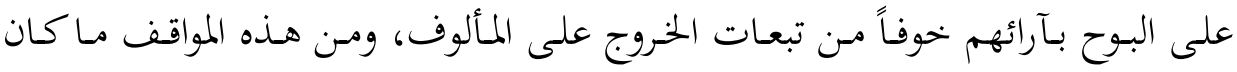
يتناوله هؤلاء العلماء من روايات يعود بعضها بها إلى عهد الصحابة رضي الله عنهم، ثم مَنْ بَعدهم من العلماء عبر القرون. لقد كان تحفّظ هؤلاء العلماء في عدم الجههر بآرائهم إيثاراً للسـلامة وخشية التورط في سجالات مع المحافظين مـ أهل العلم، وتحسباً مما قد يثيره التصريح بآرائهم من فتنة. والشيخ العلواني حين يروي مواقف هؤلاء العلماء، يتمثل عبارة

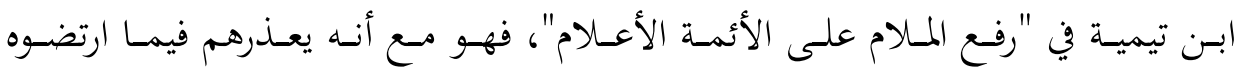
لأنفسهم، فإنه يملك الجرأة أن يصرح هو برأيه المخالف، وينشره لمحتفَّاً بالشواهد والأدلة. وكثيراً ماكنت أحاوره في مسألة الجرأة هذه، فيستفيض في إجابته ألماً وحسرة على

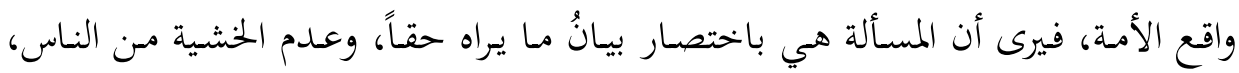

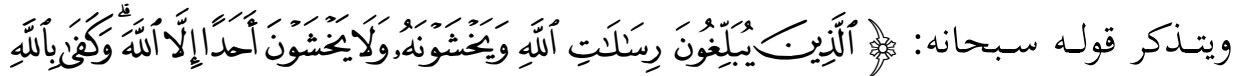

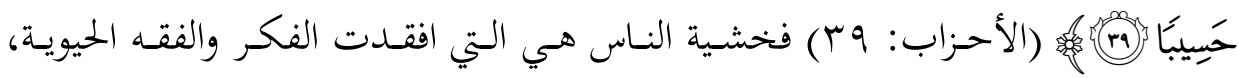

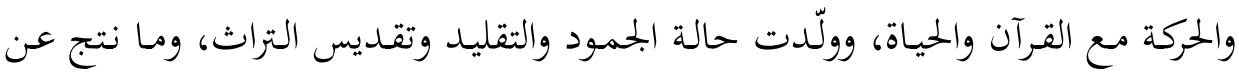
ذلك من تخلف المجتمعات الإسلامية عن مكانة الخيرية والوسطية وموقع القيادة والريادة. ومن مسوغات هذه الجرأة المطلوبة في نظر الشيخ تأكيد المرجعية العليا للقرآن الكريم بما يتصف به، وما يلزم الأمة أن تؤمن به من حاكمية القرآن وهيمنته. فالقرآن الكريم عند 
العلواني لا يقف عند كونه مصدر هداية عامة، وإنما هو قبل ذلك وبعده، المصدر المنشئ للأحكام والأفكار والعلوم، وليس في ذلك افتئاتاً على السنة النبوية؛ لأفها هي البيان الملزم

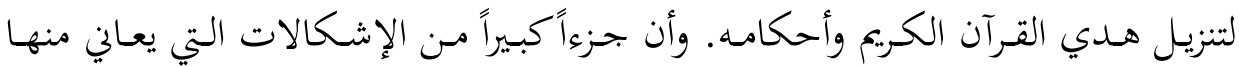

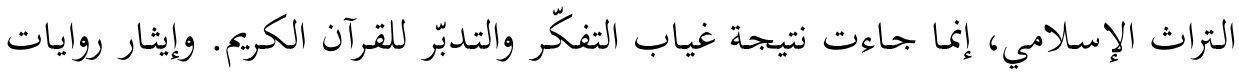

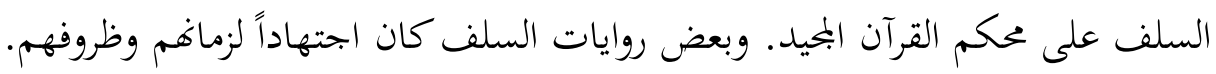

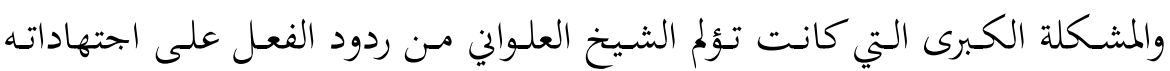

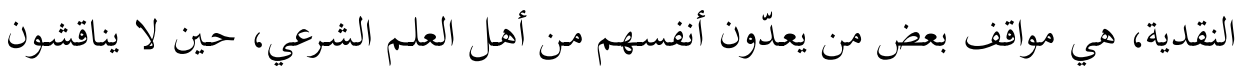

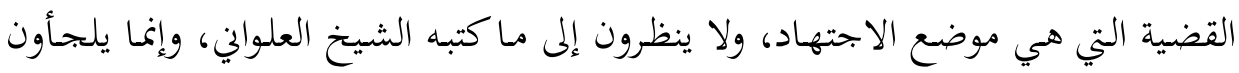

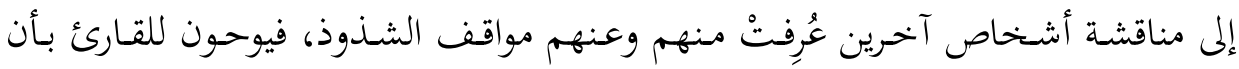

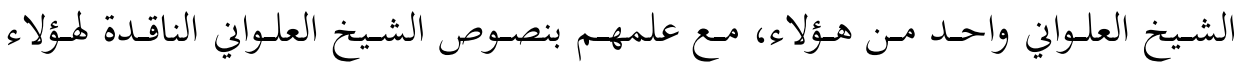
والمعارضة لمم جملة وتفصيلاً.

وكان على أهل العلم الناقدين للشيخ العلواني أن يتذكروا أن ما يأتي به هو مسائل

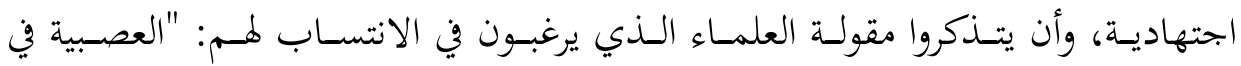

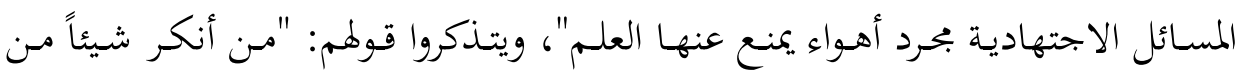

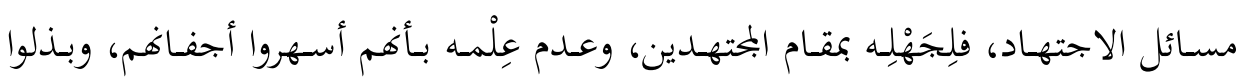

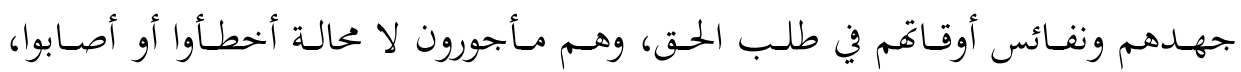

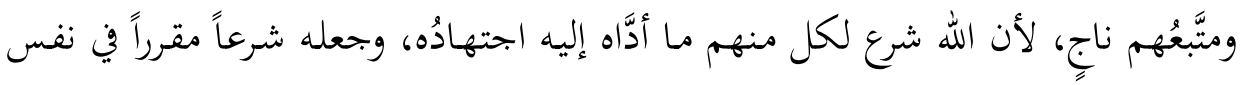

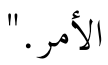

إن مـا وصـلني مـن مئـات الرسـائل والاتصـالات مـن التعزيـة بالشـيخ تـذكيراً بفضـله وعلمه، إنما يذكربي ببيت من الشعر كان الفخر الرازي يكثر من ترداده:

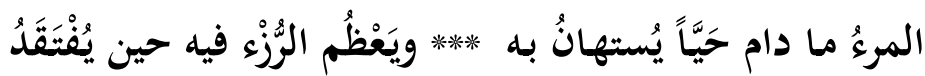

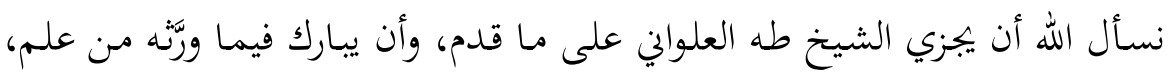

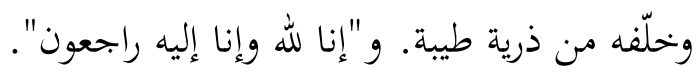

